\section{Extraction of Cobalt with Ethyl Acetate and Simultaneous Photometric Determination of Cobalt and Nickel}

\section{Extraction Studies of Metal Xanthates}

Extraktion von Kobalt mit Äthylacetat und photometrische Simultanbestimmung von Kobalt und Nickel (Studien über die Extraktion von Metallxanthaten)

Best. von Kobalt neben Nickel; Spektralphotometrie; Extraktion mit Äthylacetat als Xanthate

A. L. J. Rao and Surinder Singh

Department of Chemistry

Punjabi University, Patiala, India

Received August 22, 1972; revised November 28, 1972

In the present study, extraction of cobalt xanthate with ethyl acetate and simultaneous photometric determination of nickel and cobalt has been described. The yellow colour of nickel xanthate disappears on treatment with $72 \%$ perchloric acid whereas the colour of the cobalt xanthate remains uneffected.

Reagents and Apparatus. Potassium ethyl xanthate was prepared from distilled alcohol and $\mathrm{CS}_{2}$ and was recrystallised from acetone to remove polysulphide impurities. Other reagents were of analytical grade.

ERMA photoelectric colorimeter, Model AE was employed.

Extraction Technique. To different aliquots of the metal ion solution $1.5 \mathrm{ml}$ of xanthate reagent are added and the volume is made to $5 \mathrm{ml}$ with water in a separating funnel to which $5 \mathrm{ml}$ of ethyl acetate are added. The metal ion is extracted by a 2 -stage batch extraction technique. Both the organic extracts are mixed and diluted to $25 \mathrm{ml}$. An aliquot of this is taken and the colour absorbance is measured using a blue filter $(420 \mathrm{~nm})$. For an almost complete extraction $5 \mathrm{ml}$ of ethyl acetate are required in the $\mathrm{pH}$ range $5-9$ and $1.5 \mathrm{ml}$ of xanthate reagent (a mixture of $1 \mathrm{ml}$ of $4 \%$ xanthate and $2 \mathrm{ml}$ of $3 \mathrm{M} \mathrm{KCl}$ or $\mathrm{HCOONa}$ solution as salting out agents). The extracts are clear and are directly used for the photometric determination. The results obtained revealed that the distribution law is valid in its simple form over a range of $0.06-0.2 \mathrm{mg}$ of cobalt in $5 \mathrm{ml}$ of solution and D has been found to be almost 25 .

For photometric determination of cobalt and nickel in mixed extract, an aliquot $5 \mathrm{ml}$ is taken and absorbance is measured with blue filter. This aliquot is treated with 1-2 drops of $72 \%$ perchloric acid. After shaking the absorbance is measured with the same filter. The first absorbance corresponds to cobalt and nickel while the second one corresponds to cobalt only. The constituent metals are then determined from the calibration curves obtained under similar conditions. Fror better estimation the total absorbance (optical density) should not exceed 0.60 and this method can be used for trace analysis of cobalt in presence of high proportion of nickel.

Interferences. Manganese, aluminium, zinc, cadmium, molybdate, chromate and tungstate do not interfere. Copper is also extracted but can be masked with thiourea.

Discussion. Both these xanthates extract in ethyl acetate and other organic solvents. The possibilities of selective methods have been explored by various workers but these were time consuming and less accurate and both the metals were estimated by different methods. The technique developed in the present study is quite simple. Accuracy is about $1.5 \%$ and is quite satisfactory for routine industrial analysis of ores and alloys.

This procedure constitutes also a satisfactory qualitative test for the identification of $0.01 \mathrm{mg}$ of cobalt in $5 \mathrm{ml}$ of solution in the presence of nickel. Copper xanthate is also not affected by perchloric acid and the limit of identification of copper is observed to be $4 \mu \mathrm{g} / \mathrm{ml}$ in the presence of nickel.

\section{Dr. A. L. J. Rao}

Chemistry Department

Punjabi University

Patiala-4, India 